\title{
Combates por la memoria. La elite dirigente correntina y la invención de una tradición sanmartiniana
}

\author{
María Silvia Leoni de Rosciani \\ y María Gabriela Quiñónez. \\ Universidad Nacional del Nordeste (UNNE) \\ Resistencia, Argentina
}

A fines del siglo XIX, en el campo intelectual correntino comenzó a tomar forma una visión del pasado argentino que privilegiaba la participación de la provincia en el proceso de organización nacional y que sería utilizada en el discurso de su clase política como instrumento para combatir el centralismo y reposicionar a la elite local en un esquema político-institucional adverso a las expectativas de participación que había generado su actuación en el pasado. En ese contexto, la elite intelectual utilizó la figura del general José de San Martín, el máximo héroe nacional, intentando imponer, con relativo éxito, su condición de correntino, y ubicándolo al frente de un panteón de héroes locales, para los que también se reclamaba un lugar protagónico en la historia argentina. En este artículo analizamos el contexto político y económico que dio lugar a las solicitudes de reivindicaciones y los mecanismos utilizados por la provincia para imponer, ante la opinión nacional, a un San Martín correntino, antes que americano.

\section{La permanente actualidad de los temas sanmartinianos}

A mediados de 1995, las Asociaciones Culturales Sanmartinianas de la provincia de Misiones y de la ciudad de Gobernador Virasoro (provincia de Corrientes) comenzaron a trabajar en un plan denominado "Proyecto Yapeyú", destinado a trasladar los restos del general José de San Martín y de sus padres, Juan de San Martín y Gregoria Matorras, a la ciudad de Yapeyú, solar natal del prócer, con la finalidad de convertir a la localidad en un gran "santuario sanmartiniano" y desarrollar un polo cultural-turístico "como barrera de contención a las penetraciones, fundamentalmente culturales, a las que está peligrosamente expuesta toda la zona litoraleña de nuestra querida Argentina". ${ }^{1}$

Dos años después, el presidente de la Nación, Carlos Menem, dispuso el traslado de los restos de los progenitores desde el cementerio porteño de

1 La información sobre el "Proyecto Yapeyú" y el traslado de los restos se encuentra en la página www.misionet.com.ar/acsanmartiniana. 
La Recoleta a Yapeyú. A partir de allí, se constituyó la Comisión Biprovincial Ejecutora del Proyecto Yapeyú, integrada por los Gobernadores de las provincias de Corrientes y de Misiones y las autoridades de la Asociación Cultural Sanmartiniana de Gobernador Virasoro y de Misiones. El apresurado traslado de los restos de los padres de San Martín se debió a la polémica generada por esta medida, en contra de la cual se había formado en Buenos Aires una comisión "antitraslado". Indudablemente, el proyecto de traslado de los restos del "padre de la patria" tuvo una más enconada resistencia y debió ser abandonado.

En el acto efectuado en Yapeyú, en representación de la Comisión Biprovincial, Enrique Gentiluomo destacó que "están de vuelta en el escenario de sus luchas, Juan de San Martín y Gregoria Matorras que tuvieron que pasar años en el cementerio de la Recoleta por una disposición irracional que ya cae en lo ridículo, [de quienes] pretenden erigirse guardianes autodestinados del patrimonio histórico-cultural argentino". ${ }^{2}$

Como se advierte, los debates en torno a la figura de San Martín, en los cuales el tema Yapeyú tiene centralidad, persisten aún hoy en la Argentina. No se discuten aspectos de su personalidad ni su actuación, sino que se polemizan cuestiones que no afectan a las mismas. Así lo manifiesta la última polémica (en el año 2000, "Año del Libertador General San Martín"), de gran repercusión en los medios, suscitada en torno a quiénes fueron los verdaderos padres del héroe.

Por su parte, el tema Yapeyú ha tenido una larga discusión que se proyecta hasta la actualidad, y que nos permite analizar las vinculaciones establecidas entre historiografía, memoria y política en la Argentina, a la luz de lo que consideramos la invención de una memoria sanmartiniana en la provincia de Corrientes por parte de su elite. Ella reconoció, desde fines del siglo XIX, la importancia de los símbolos y de las interpretaciones históricas para fundar su oposición al centralismo de Buenos Aires; éste, a su vez, se fundamentaba en la construcción de una historia nacional que desconocía las perspectivas provinciales. La apropiación de la memoria del héroe máximo de los argentinos constituiría, en este contexto, una valiosa reivindicación para la postergada provincia.

Desde que se comenzó a escribir la historia de la Nación Argentina, se le asignó a José de San Martín un papel principal. Su consagración como

2 Ibídem 
héroe nacional se realizó a través de los textos que se propusieron reparar los juicios - considerados injustos- vertidos por sus contemporáneos. Los primeros trabajos que adoptaron este enfoque fueron los artículos de Domingo F. Sarmiento, a partir de 1841, y el Bosquejo biográfico del Gral. José de San Martín, de Juan María Gutiérrez (1863). Quedaría definitivamente consagrado por la historiografía con la obra canónica de Bartolomé Mitre, Historia de San Martín y de la emancipación sudamericana (1887). ${ }^{3}$ Paralelamente, la erección de la estatua ecuestre en la plaza de Marte en Buenos Aires (1862) y la repatriación de sus restos, en 1880, con los consecuentes actos de homenaje, constituyeron otros indicadores del lugar que se le reservaba en la construcción de la historia patria.

Hacia fines del siglo XIX, desde el Consejo Nacional de Educación se advirtió la necesidad de revivir las fiestas patrias como medida para contrarrestar el creciente cosmopolitismo que afectaba a la sociedad argentina, más concretamente, a la porteña. En un esfuerzo por "construir la nacionalidad" se estableció un ritual cívico para las celebraciones, se otorgó gran importancia a los símbolos patrios, se multiplicó la imaginería en torno de las figuras de los héroes y se orientó la enseñanza hacia una educación esencialmente nacional. ${ }^{4}$

En este marco, el homenaje al general San Martín comenzó a ocupar un lugar central en las celebraciones de mayo y julio, ${ }^{5}$ hasta quedar elevado a la condición de padre de la Patria. Su personalidad revestida de altos valores morales, su heroísmo, exaltado por las hazañas militares que permitieron materializar la independencia argentina y americana, y su muerte en el exilio voluntario, fueron los elementos que permitieron redimensionar su figura. En un contexto singular, alejada de los problemas sociales que afectaban a Buenos Aires aunque, al mismo tiempo, atenta a sus posibles efectos, la elite dirigente correntina utilizó la figura del Libertador según la orientación que proponía el gobierno nacional, pero también con un peculiar sentido reivindicatorio.

3 Kohan, Martín: "De héroe militar a Santo de la espada. La consagración histórica de José de San Martín”, en Todo es Historia, n. ${ }^{\circ}$ 397, agosto, 2000, págs. 74-85

4 Ver Bertoni, Lilia Ana: "Construir la nacionalidad: héroes, estatuas y fiestas patrias, 18871891", en Boletín del Instituto de Historia Argentina y Americana "Dr. Emilio Ravignani”, Buenos Aires, n. ${ }^{\circ}$ 5, 1992, págs. 77-111.

5 Las dos efemérides más importantes del calendario cívico argentino corresponden al 25 de mayo, fecha en que se conmemora el establecimiento del primer gobierno patrio, y el 9 de julio, día de la Independencia. 


\section{Las percepciones de la elite correntina en el cambio de siglo: De la provincia "heroica" a la provincia "postergada"}

La finalización de la lucha contra Rosas, en la que cinco ejércitos libertadores correntinos habían tenido gran protagonismo, y el logro de la Constitución nacional en 1853, que inició el proceso de organización institucional del país culminado en 1880, generó una gran expectativa en la elite correntina respecto del papel que desempeñaría en el futuro nacional. Por ello buscó reencauzar sus energías sociales en la senda del progreso, bajo el concepto de que su destacada actuación en el pasado reciente, sumada a la potencialidad de sus recursos naturales, la avalaban para ocupar un lugar central en el esquema político y económico nacional, al que pretendía acceder bajo el honroso título de "provincia organizadora". ${ }^{6}$

Pero, con la incorporación de la Argentina a la economía mundial a través de la adopción del modelo agroexportador, los miembros de la elite comenzaron a advertir que la posición de la provincia en el esquema económico que se definía no respondía a las expectativas que se habían suscitado desde mediados del siglo XIX, las cuales demostraban un alto grado de optimismo acerca de las potencialidades de su territorio, exaltadas y transmitidas de generación en generación.

El sentimiento colectivo de excesiva confianza en el futuro de la provincia tardaba en materializarse, y derivó paulatinamente, desde fines del siglo XIX, en un sentimiento de postergación, que se acentuaba al compararse la situación de Corrientes con el despegue de sus vecinas del litoral, con las que había compartido el protagonismo de los años de lucha por la organización nacional. Esta realidad alejada de las expectativas, también incluía una participación cada vez menor en las cuestiones nacionales, intervenciones federales frecuentes, denunciadas como ataques a su autonomía, y el avance de los poderes nacionales que debilitaba cada vez más a las provincias, burlando las fórmulas prescriptas en la Constitución, por la que Corrientes tanto había bregado. La situación era percibida como injusta por parte de la elite correntina, y fue censurada ininterrumpidamente.

En 1911, una editorial de "La ilustración correntina", publicación que expresaba el pensamiento de los hombres de la generación del Centenario, afirmaba que Corrientes, que había estado durante mucho tiempo a la van-

6 Ver Quiñónez, María Gabriela: "Itinerario de la memoria. La “cruzada libertadora” en la historia y la política de Corrientes”, en XIX Encuentro de Geohistoria Regional, Corrientes, 1999, págs. 381-397 
guardia de las acciones en el terreno político, para salir de la situación de estancamiento en que se hallaba y ocupar posiciones acordes con las pretensiones históricas de su elite, debía seguir:

"El ejemplo siempre fuerte y fecundo que nos revelan algunas provincias hermanas: Buenos Aires, Santa Fe, Entre Ríos, Córdoba, Tucumán, con sus extensas zonas llenas de sembrados... con la labor febril de sus molinos, destilerías, ingenios de azúcar, etc., cuya influencia juega papel tan decisivo en la prosperidad del país...”.?

La adopción de este modelo permitiría "reconstruir nuestra grandeza debilitada" y aportar al progreso nacional, al mismo tiempo que beneficiarse de él.

La generación del Centenario analizó las causas de tal postergación. Entre los factores que obstaculizaban el desarrollo económico apuntarían la supervivencia de los latifundios, el limitado avance de los medios de transporte y la falta de crédito para la actividad agrícola. La escasa difusión de la agricultura y de la industria y el fracaso de los intentos colonizadores habían causado el desarraigo y su consecuencia inmediata, la emigración. ${ }^{8}$ Las potencialidades naturales que no habían sido suficientemente aprovechadas, debían serlo sin demora :

"Corrientes continúa ahí, en el sitio que le señalara el conquistador, conservando casi íntegramente toda la fisonomía física de la época en que se fundó; se perpetúa a través de los tiempos y con éstos perpetúa también los mismos dones que siguen provocando las mismas incitaciones a la labor del hombre... Y se ha de perpetuar, y ha de atraer a sí todas esas febriles manifestaciones de la inteligencia, del brazo, del capital, que se exhiben potentes allí abajo, en Buenos Aires, en Santa Fe, en Córdoba, por la fuerza de la necesidad y en cumplimiento de leyes naturales que fatalmente se imponen". ${ }^{\circ}$

La elite correntina se propuso entonces ocupar el lugar que consideraba le correspondía a la provincia en el contexto nacional: uno de los instrumentos utilizados fue la reivindicación de su aporte histórico al proceso de construcción del orden institucional argentino.

Los intelectuales correntinos dejaban entrever su disconformidad con el lugar que se les había adjudicado a sus héroes en el marco de la historia

7 La Ilustración Correntina, Corrientes, año I, n. ${ }^{\circ}$ 1, Febrero, 1911, s/p.

8 Para este tema, ver: Conferencias de Extensión Secundaria y Cultural, Corrientes, 1926; Basterretche, Juan F: Corrientes, sus actuales riquezas y su grandeza futura, Corrientes, 1912; y Serrano, Pedro Benjamín: Guía General de la Provincia de Corrientes, Corrientes, 1910

9 Basterretche: Corrientes, sus actuales riquezas..., pág. 30 
nacional, un lugar periférico equivalente al que se le asignaba a la provincia en la "nueva Argentina"; aquellos héroes "esencialmente" correntinos, como Genaro Berón de Astrada o Joaquín Madariaga, cuya actuación estaba vinculada a las luchas por la organización nacional, o figuras como la de Pedro Ferré, ligada a la defensa del federalismo, no trascendían en una historia argentina teñida de un fuerte centralismo. Ante esta situación, intentaron crear un panteón de héroes locales en el cual la figura de San Martín encabezaba a otros "comprovincianos", también "libertadores", pero que habían desarrollado un combate en otro frente: la lucha contra la "tiranía rosista". Mientras el primero era símbolo de unidad americana, los segundos simbolizaban el federalismo, la defensa de la autonomía correntina, en suma: "hacer la Nación en la provincia" ${ }^{10}$ Ambos proveían los ideales a los que aspiraban los correntinos.

Al Libertador de América se le adjudicó la controvertida condición de "correntino", ya que había nacido en Yapeyú, población ubicada sobre la margen izquierda del río Uruguay. El lugar había sido asiento de una reducción jesuítica fundada en 1627 y, al producirse la expulsión de los jesuitas, se convirtió en la cabecera de un gobernador, cargo que ocupó el padre de San Martín; allí nació el Libertador en 1778. Como consecuencia de la disgregación de la provincia guaranítica de Misiones a comienzos del siglo XIX, su territorio se repartió entre las nuevas naciones surgidas en la región. Argentina incorporaría las Misiones Occidentales, sobre las cuales la provincia de Corrientes (que fuera creada en 1814) realizó una importante política pobladora entre 1827 y 1881: Yapeyú sería incorporado a la provincia en $1830 .{ }^{11}$ Organizado definitivamente el país, se produjo un prolongado conflicto jurisdiccional entre los gobiernos nacional y de la provincia de Corrientes sobre la región misionera, que el primero solucionaría en 1881 mediante una ley que creaba el territorio nacional de Misiones, que abarcaba la zona ubicada al este del río Aguapey. Esta medida fue sentida como un despojo por la provincia, cuyos reclamos serían constantes. De allí la reivindicación de sus derechos que importaba rescatar la "correntinidad" de San Martín.

10 Véase Leoni de Rosciani, María Silvia: “El aporte de Hernán Félix Gómez a la historia y la historiografía del Nordeste", en Folia Histórica del Nordeste, Resistencia, IIGHI-CONICET, n. ${ }^{\circ}$ 12, 1995, pág. 55; "La historia política en Corrientes y sus historiadores", en Nordeste, Investigación y Ensayos, Facultad de Humanidades, n. ${ }^{\circ}$ 10, 1999, pág. 148; y Quiñónez: Itinerario de la Memoria..., págs. 381-383

11 Schaller, Enrique César: "La provincia de Corrientes y el poblamiento de Misiones", en Unidad y diversidad en América Latina: conflictos y coincidencias, Buenos Aires, 2000, t. II, pág. 561. 


\section{Yapeyú, Corrientes y la construcción de lugares de memoria sanmartiniana}

Los esfuerzos correntinos se concentraron inicialmente en recuperar el solar natal de San Martín, para convertirlo en centro de los homenajes a su memoria. Ya en 1859, el gobernador Juan Pujol, en su mensaje a la legislatura correntina, proponía restablecer con el nombre de General San Martín el pueblo de Yapeyú, que había sido destruido por el ataque de Francisco das Chagas Santos en 1817. Si bien su objetivo era fundar allí una colonia agrícola, apelaba a fundamentos de reparación histórica:

"El gobierno, tan interesado como el que más en conservar la memoria de los hechos gloriosos como la de los monumentos que ilustran la historia de la provincia, no puede ni debe dejar de llamar la atención de V.H. sobre la importancia histórica y nacional de restablecer el antiguo y extinto pueblo de Yapeyú, lugar del nacimiento de uno de los más famosos caudillos de la libertad americana, el general San Martín... ningún homenaje más digno pudiéramos ofrecer a la memoria de tan ilustre compatriota, como el de levantar de nuevo el techo arruinado de su hogar doméstico e impedir que el casco de las bestias continúe profanando el lugar de su cuna. Cuando el Poder Ejecutivo se dirige a la notoria ilustración y patriotismo de V.H. es por demás abundar en reflexiones sobre la medida propuesta, y cuánta honra y merecido elogio se granjeará del pueblo argentino vuestra soberana resolución". ${ }^{12}$

Como se desprende de esta iniciativa, con anterioridad a la erección del primera monumento a San Martín en territorio argentino - recordemos que la primer estatua del héroe data de 1862 - el gobierno de Corrientes ya había advertido sobre la importancia de erigir un lugar de memoria. Sin embargo, este proyecto no llegó a concretarse; diez años después, el gobernador José Miguel Guastavino se propuso restaurar la casa natal, destinándola a una escuela y nombró una comisión para que individualizara el sitio, objetivo que tampoco alcanzó éxito.

El 12 de octubre de 1892, en medio de la revolución organizada por el partido liberal contra el gobierno autonomista de Antonio Ruiz, el $3^{\circ}$ ejército de línea se asentó en la localidad de Yapeyú. Como la tradición señalaba a una ruinosa construcción como la casa en la que naciera el General San Martín, se levantó la información entre los pobladores, la cual

12 Citado por Leguizamón, Martiniano: La casa natal de San Martín. Estudio crítico presentado a la Junta de Historia y Numismática Americana con documentos, vistas y planos aclaratorios, Buenos Aires, 1915, págs. 74-75. 
fue elevada al Ministerio de Guerra. ${ }^{13} \mathrm{Al}$ año siguiente, se organizó una comisión de homenaje, cuya tarea tuvo un principio de ejecución en 1895.

En 1899, el ingeniero Florencio de Basaldúa, debido a los informes contradictorios sobre la ubicación de la casa, decidió consultar a los vecinos más ancianos y labró un acta que determinaba el lugar exacto. Finalmente, el 12 de octubre de ese año, se realizó en Yapeyú el primer homenaje a San Martín, reconociéndose al poblado como la cuna del Libertador, y a la construcción individualizada, como su casa natal. Unos días antes, Roberto D. Oliver, responsable del periódico Corrientes, destacaba la importancia de la recuperación de la memoria sanmartiniana:

\begin{abstract}
"Pasó la anarquía, se derrumbó el despotismo y aquella figura hasta cierto punto olvidada en la vorágine de las pasiones y de los odios, ha resurgido enérgicamente acentuada en la conciencia nacional, como aquellos monumentos que el genio romano, a despecho del tiempo y de las vicisitudes, hace llegar hasta nosotros, admirables por sus grandiosas proporciones y su belleza artística". ${ }^{14}$
\end{abstract}

Como parte de la conmemoración en Yapeyú, se realizó un tedéum y posteriormente se inauguró en la plaza principal, sobre una columna, un busto de San Martín. Los actos centrales, que precedieron a los festejos populares, fueron presididos por el gobernador de la provincia, Juan Esteban Martínez, y el general José Garmendia en representación del gobierno nacional. La celebración adquirió ribetes internacionales por la presencia de un delegado del ejército chileno, un representante del gobierno peruano, los guerreros del Paraguay, una cañonera de la armada brasileña y una delegación del Colegio Nacional del Uruguay; fueron acompañados del público que llegó desde distintos rincones de la provincia de Corrientes y desde la Capital Federal. Esta última se hallaba representada por el delegado de la Universidad de Buenos Aires, un grupo de damas que contribuyó con la construcción de una capilla y los periodistas que difundieron las crónicas a través de los diarios nacionales. ${ }^{15}$ En apoyo de esta iniciativa, diría Estanislao Zeballos, director de la influyente Revista de Derecho, Historia y Letras:

“...la columna vulgar y pobre de Yapeyú vale, sin embargo, como iniciativa generosa de soldados humildes destinada a ser substituida por el arte y el bronce, cuando otras

13 Archivo Histórico de la Provincia de Corrientes. Fondo Hernán Félix Gómez. Carpeta n. ${ }^{\circ}$ 46. "Las Ruinas de la Casa natal del Libertador de Yapeyú y la prueba de su autenticidad".

14 "Editorial", en Corrientes, Corrientes, año V, n. ${ }^{\circ}$ 555, 10 de octubre de 1899, pág. 1.

15 Corrientes, año VI, n. ${ }^{\circ} 557,17$ de octubre de 1899 , pág. 1 
generaciones, redimidas del pecado original de nuestros días, cultiven ideas más puras de civismo". ${ }^{16}$

En esa oportunidad, se labró un acta que dejaba constancia de la donación del solar al gobierno de Corrientes por parte de un vecino. También se inauguró la iglesia parroquial en el lugar que ocupaba la antigua capilla, en homenaje a la memoria de San Martín.

La provincia ya contaba con un lugar de memoria, el cual se convertiría en centro de peregrinaciones. En este sentido, se había adelantado a las otras dos provincias que contaban con lugares que podían erigirse en centros de la memoria sanmartiniana: Santa Fe, donde se había desarrollado el primer combate del Ejército de Granaderos a Caballo creado por San Martín, en los campos de San Lorenzo, en las proximidades del convento de San Carlos; ${ }^{17}$ y Mendoza, donde se había establecido el campamento del Plumerillo, base del Ejército de los Andes. ${ }^{18}$

La ciudad capital de la provincia aún no tenía referentes materiales vinculados con San Martín. La imaginería cívica de la ciudad de Corrientes se reducía a una estatua del sargento Juan Bautista Cabral, ${ }^{19}$ que se encontraba ubicada en el centro de la plaza San Juan Bautista (1887), y a las columnas conmemorativas de la fundación de la ciudad (1828) y del juramento de la Constitución Nacional (1860), emplazada esta última en el centro de la plaza Mayo e integrada por los bustos de Mariano Moreno, Cornelio Saavedra, Bernardino Rivadavia y José de San Martín, coronados por la estatua de la Madre Patria. ${ }^{20}$

En 1890, el periódico "El Litoral” proponía elevar un monumento a San Martín en el Campo de Marte, al advertir que "en tanto que el mártir de San Lorenzo tiene erigida su estatua en la plaza que lleva su nombre... el vencedor de ese mismo combate... no tiene aún el pedestal que reclama en esta capital, en nombre de sus servicios a la patria." Y reforzaba este reclamo argumentando que "San Martín tiene para nosotros el doble título

16 Citado por Gómez, Hernán Félix: Yapeyú y San Martín, Buenos Aires, 1923, pág. 28.

17 El gobernador santafesino Nicasio Oroño había propuesto la expropiación del convento de San Carlos y sus adyacencias, que se amplió por una ley que también destinaba una partida para erigir una columna en el lugar del combate (1889).

18 El sitio estuvo olvidado hasta el año 1899, en que un grupo de mendocinos levantó una pirámide con los escudos de Argentina, Chile y Perú. El 17 de agosto de 1932 se construyó un pórtico alegórico y se colocaron los cañones del Ejército de los Andes. Ver Vigil, Carlos: Los monumentos y lugares históricos de la Argentina, Buenos Aires, 1959, pág. 282

19 Fue un correntino, integrante del Regimiento de Granaderos a Caballo, quien salvó la vida de San Martín en el combate de San Lorenzo.

20 Gómez, Hernán Félix: La ciudad de Corrientes, Corrientes, 1944, pág. 65. 
de argentino y de correntino y para la historia el de Libertador glorioso....". ${ }^{21}$ Esta idea fue convertida en ley recién en 1902. En esta oportunidad, se resolvió ubicar la estatua en la plaza Mayo, en reemplazo de la columna conmemorativa de la jura de la Constitución. La norma ordenaba que una comisión de ciudadanos se encargara de organizar las suscripciones populares en toda la provincia.

Por esos años, el fervor patriótico había ido creciendo a medida que se agravaba el conflicto de límites con Chile. En mayo de 1902, las celebraciones organizadas por la Liga Patriótica habían adquirido un brillo inusitado, y los fondos obtenidos en el desarrollo de los números programados, que inicialmente debían destinarse a la adquisición de un acorazado para la armada nacional, al diluirse el conflicto, fueron puestos a disposición de las comisiones pro-monumento para que contribuyeran al enriquecimiento de la imaginería cívica en la ciudad. ${ }^{22}$ Paralelamente, por una ley provincial, se dispuso la erección de un monumento en homenaje a los "mártires de la lucha contra la tiranía", propuesta que circulaba ya desde los años ochenta..$^{23}$ Estas iniciativas revelan la preocupación por dotar a Corrientes de referentes materiales para la construcción de su memoria histórica.

La estatua ecuestre de San Martín debía ser una réplica de la existente en Buenos Aires. Se le encargó al escultor José García la realización de un monumento similar al que recientemente ejecutara para las ciudades de Santa Fe y Mendoza, y se comisionó a los doctores Valentín Virasoro y Manuel Florencio Mantilla, residentes en la Capital Federal, y a los legisladores nacionales Juan José Silva y J. Ismael Billordo para que supervisaran la fundición de la estatua, mientras en la capital correntina se iniciaban los preparativos de la celebración inaugural. En proximidades de las fiestas mayas de 1904, la estatua se hallaba en el puerto de Corrientes. El desembarco movilizó a los estudiantes secundarios, que acudieron al muelle para

21 "Una estatua", en El Litoral, Corrientes, año III, n. ${ }^{\circ}$ 551, 31 de enero de 1890, pág. 1.

22 Un decreto del poder ejecutivo provincial estableció la comisión central y autorizó la formación de comisiones auxiliares y departamentales para encargarse de las suscripciones: Corrientes, año VIII, n. ${ }^{\circ} 838,5$ de noviembre de 1902, pág. 4 . En la ciudad de Corrientes se constituyó una Comisión Popular presidida por Rómulo Amadey e integrada por Lorenzo J. Aquino, Eulogio Cruz Cabral, Manuel Cabral, Leandro Caussat, Adolfo Contte, Ramón Díaz de Vivar, Ernesto Ezquer, Miguel L. Jantus, Emiliano Montiel, Enrique Roibon, Guillermo Rojas, Conrado Romero, Joaquín Sayanca, Joaquín Vedoya, Avelino Verón, Juan Ramón Vidal y el delegado eclesiástico presbítero Luis María Niella. A ésta se sumaron comisiones auxiliares de damas y caballeros. Serrano, P. Benjamín: Guía General de la Provincia de Corrientes, Corrientes, 1904, pág. 261

23 Corrientes, año VIII, n. ${ }^{\circ} 837,1$ de noviembre de 1902, pág. 4 
presenciar el descenso. Los esfuerzos para bajarla a tierra y llevarla hasta el sitio de su emplazamiento, donde se había iniciado la construcción del pedestal, insumieron varias jornadas en las que la estatua, en medio de la expectativa general, avanzó lentamente sobre un entarimado por las calles Córdoba y Mayo. ${ }^{24}$

Por esos días se organizaba una gran apoteosis dedicada a la memoria de San Martín en la ciudad de Mendoza, para lo cual los representantes mendocinos en el Congreso Nacional gestionaron un subsidio. El diputado correntino Juan José Silva utilizó esa circunstancia para solicitar, a su vez, un subsidio que permitiera financiar la fiesta de inauguración del monumento, que coincidiría con la festividad de la Virgen de la Merced, el 24 de septiembre. Numerosos proyectos aparecían en la prensa correntina para integrarse a los festejos y la gran cantidad de sujetos y asociaciones que intervinieron en la toma de decisiones prolongaron los preparativos, mientras que se postergaba indefinidamente la inauguración, debido a que el entorno del monumento no se hallaba en buen estado.

Las comisiones entraron en conflicto con el gobierno y la prensa reclamaba la celebración; mientras tanto, el gobernador José Rafael Gómez, en un acto improvisado, el 31 de marzo de 1905, decidió dejar la estatua librada a la admiración pública, interrumpiendo abruptamente los preparativos populares. Dicha inauguración coincidió con el aniversario de la batalla de Pago Largo: "la primera de las jornadas contra la tiranía", explicación utilizada por el oficialismo para fundamentar tal medida. ${ }^{25}$

La estatua ecuestre cumplió su papel de referente material desde antes de su inauguración. En agosto de 1904, en cercanías del aniversario del fallecimiento de San Martín, la prensa invitó a las asociaciones a realizar un homenaje al Libertador, y la Sociedad 2 de Agosto del Colegio Nacional tomó la iniciativa, organizando un concurso artístico y literario. En 1905, las fiestas mayas organizadas por el Centro Intelectual tuvieron como acto popular más destacado una procesión cívica que, partiendo de la Plaza Cabral, luego de recorrer las principales calles de la ciudad, finalizó con actos al pie de la estatua del Libertador. Desde ese año y especialmente a partir del centenario, las celebraciones patrias crecieron en brillo y partici-

24 El Trabajo, Corrientes, año VIII, n. 767 y 769, 27 de mayo y 3 de junio, 1904, pág. 2

25 Los periódicos liberales criticaron al gobierno por el manejo del subsidio nacional obtenido por el diputado Juan José Silva, mientras la prensa autonomista justificó la decisión del gobernador de utilizarlo para el arreglo de la plaza. La Provincia, Corrientes, año V, n. ${ }^{\circ} 455,6$ de abril de 1905, pág. 4. 
pación cívica, con la intervención en los preparativos de las celebraciones populares de las asociaciones que nucleaban a los estudiantes y, desde 1910, especialmente del Centro de Estudiantes Secundarios del Colegio Nacional. En el interior de la provincia también surgieron proyectos para la construcción de monumentos a San Martín, como en los casos de las localidades de Goya y Santo Tomé que, sin embargo, tardaron en concretarse.

\section{La "cuna del héroe" en el centro del debate}

El propósito de convertir a las ruinas de Yapeyú en un monumento central para la memoria sanmartiniana, condujo a una polémica que se extendería a lo largo de una década y que alcanzaría repercusión popular y proyección en el ámbito nacional. Ello nos demuestra el gran interés despertado por la historia local en la opinión pública correntina y la importancia asignada a estas cuestiones por parte de los gobiernos provinciales y nacionales, que reconocieron la utilidad política de la historia.

Debe tenerse en cuenta que Corrientes atravesó, en la primera mitad del siglo XX, una etapa de desarrollo historiográfico, manifiesto en una importante labor heurística, una rica producción, que incluye obras fundamentales, y polémicas que alcanzaron amplio eco, aun fuera de los límites provinciales. Los movimientos historiográficos prevalecientes en Buenos Aires tuvieron su proyección en la provincia, que buscó incorporar los adelantos metodológicos introducidos por aquellos. ${ }^{26}$ En este contexto historiográfico, tendría lugar la polémica en torno al solar natal de San Martín.

En 1915, el diputado por Corrientes Ramón A. Beltrán presentó en la Cámara de Diputados de la Nación un proyecto de ley por el cual se autorizaba al Poder Ejecutivo la compra de la manzana de terreno ocupada por las ruinas de la casa de San Martín, "con objeto de restaurarla y conservarla como un monumento de gratitud nacional". Aprobado el proyecto en el Congreso, fue sancionado como ley n. ${ }^{\circ}$ 9655. El Poder Ejecutivo designó una comisión compuesta por Emilio Frers, José Marcó del Pont y Juan A. Pradére, para que propusiera las medidas reglamentarias y dirigiera el cumplimiento de esta ley. Producida la renuncia de Marcó del Pont, fue reemplazado por Beltrán.

26 Leoni de Rosciani, María Silvia: "El Nordeste", en Academia Nacional de la Historia, $L a$ Junta de Historia y Numismática Americana y el movimiento historiográfico en la Argentina, Buenos Aires, 1996, t. II, pág. 112. 
Esta ley provocaría un intenso debate, reflejado en los principales periódicos del país, que se inició el 2 de noviembre, con un artículo de Juan Esteban Guastavino sobre "La casa de San Martín", publicado en el diario La Nación, en el cual, tras señalar la falta de fundamentos sólidos para la determinación del solar, amonestaba:

\footnotetext{
"Estamos pues en presencia de un hecho histórico que debe esclarecerse sin dubitación, para que el cumplimiento de la ley nacional, a que se liga un noble anhelo patriótico de los argentinos, no padezca de los visos de una incomprensible veleidad histórica que jamás podría armonizar con los caracteres severos del héroe que la motiva”. ${ }^{27}$
}

Dos días después, el mismo diario, bajo el título "Las ruinas de Yapeyú", se hacía eco de esta preocupación y advertía que, si no había documentos o antecedentes válidos, era prudente disipar la duda antes de cumplir la ley que, de lo contrario, consagraría "sin suficiente autoridad por sí misma, un hecho histórico que puede no ser histórico, ni hecho siquiera".

A la polémica sostenida entre Beltrán y Guastavino, se sumaría Carlos E. Zuberbhuller, quien publicó el artículo "La casa histórica de Yapeyú. Un antecedente significativo", en el cual abonaba la hipótesis de que San Martín no había nacido en Yapeyú sino en un lugar llamado Santoré, que pudo haber sido Santo Tomé o bien una quinta en las afueras de Yapeyú. Se agregaría Pradére, abriendo un nuevo plano en el debate, pues en $L a$ Nación del 17 de noviembre, afirmaba que San Martín no había nacido en 1778 sino en 1781, fundándose en su foja de servicios y en el acta de esponsales; pero se excusaba de emitir opinión sobre los otros aspectos en debate, dadas las funciones que debía cumplir en la Comisión. Se inició así un intercambio, a través del diario, esta vez entre Pradére y Guastavino. Este último reuniría sus artículos y otros documentos en un opúsculo titulado La cuna de San Martín.

En medio del debate, el gobierno de Corrientes dictó un decreto el 15 de noviembre, para contribuir al cumplimiento de la ley 9655. Para precisar el lugar exacto de las ruinas, comisionó a Juan Wenceslao Gez, director de la Escuela Normal de Profesores de Corrientes y miembro correspondiente de la Junta de Historia y Numismática Americana, quien elaboró un informe negativo, publicado en La Prensa y La Nación y, al reiniciarse la polémica en 1923, se reproduciría en el primer número del Boletín de la Junta. ${ }^{28}$

27 Guastavino, Juan Esteban: La cuna de San Martín, Buenos Aires, 1915, pág. 24.

28 Gez, Juan W: "Las ruinas de Yapeyú", en Boletín de la Junta de Historia y Numismática, Buenos Aires, n. ${ }^{\circ} 1,1924$. 
Planteado el tema en el seno de la Junta de Historia y Numismática Americana, ésta designó una comisión integrada por Martiniano Leguizamón, Adolfo Decoud y Carlos I. Salas, para realizar una investigación histórica sobre este tema. Leguizamón, quien ya venía realizando estudios sobre el mismo, elaboró un extenso informe, con un dictamen negativo, que fue aprobado por la Junta, la cual ordenó su publicación. Se editó así $L a$ casa natal de San Martín. Estudio crítico presentado a la Junta de Historia y Numismática Americana con documentos, vistas y planos aclaratorios (1915), que determinaba la inconsistencia de la tradición y la precipitación con que se pretendió recogerla, desconociendo importantes antecedentes históricos. Concluía: "en el fondo de este asunto sólo existe la ficción de una bella leyenda, cuyo misterio acaso nunca será dado esclarecer; pero creemos también que silenciando la verdad, no habríamos cumplido la tarea que la Junta nos encomendó...”. ${ }^{29}$

Ante el cariz que tomaban los acontecimientos, vecinos y funcionarios de Yapeyú enviaron una nota a la comisión oficial, en la que solicitaban continuar con la tarea, pues "animados de un sentimiento patriótico y justiciero, no podemos permanecer impasibles e indiferentes al juicio vertido por ciertas personas para desvirtuar la tradición histórica transmitida de padres a hijos, sobre la autenticidad de las ruinas". ${ }^{30}$ No obstante, Frers y Pradére comunicaban, a principios de 1916, que la comisión había decidido dar por finalizado su cometido, con las reservas efectuadas por Beltrán. Terminaba así la primera parte de este debate. Según Hernán Gómez, historiador correntino al que nos referiremos más adelante, el fracaso en la aplicación de la ley se debió a los errores que ésta encerraba: no tenía en cuenta las donaciones realizadas con anterioridad del terreno ocupado por las ruinas, se refería erróneamente a la casa "propiedad" de San Martín, y proponía su restauración, lo que era impracticable. ${ }^{31}$

En Corrientes continuaron los esfuerzos de quienes defendían la autenticidad de las ruinas, como Isidro Nin, director del periódico Nueva Época, de Paso de Los Libres, el presbítero Eduardo J. Maldonado, cura párroco de Yapeyú, que publicó La cuna del héroe (1918) y Tomás Frías, autor de El solar de San Martín (1921); la importancia asignada al tema en

29 Leguizamón: La casa natal..., pág. 56

30 Maldonado, Eduardo J: La cuna del héroe. Antecedentes que comprueban la autenticidad de las ruinas de la casa donde nació el Libertador don José de San Martín en Yapeyú, Provincia de Corrientes (República Argentina), Buenos Aires, Peuser, 1918, pág. 25.

31 Gómez: Yapeyú..., pág. 181. 
Corrientes se señala en la tapa de este último libro: "Con el propósito patriótico de contribuir al esclarecimiento de un hecho capital en la Historia de la Nación Argentina". Desde 1916, comisiones populares de Yapeyú y Paso de los Libres continuaron moviendo a la opinión pública en este sentido.

\section{San Martín y Yapeyú: ¿instrumentos para la reivindicación?}

Al mismo tiempo que se lograba la sanción de la ley 9.655, en 1915, un grupo de correntinos residentes en Buenos Aires comenzó a organizarse para tributar un homenaje al general San Martín en el 65 aniversario de su fallecimiento. En medio de los preparativos y como parte de las celebraciones, de la asamblea del día 15 de agosto surgió el Centro Correntino "General San Martín".

Tras la propuesta inicial destinada a instituir un espacio de homenaje al padre de la patria, se manifestaba la formación de un nucleamiento de carácter político, que reflejaba en sus fines el pensamiento, las expectativas y las inquietudes de la elite dirigente correntina. El centro estaba integrado por personalidades destacadas, tanto por los cargos que desempeñaban como por el lugar que ocupaban en el campo intelectual correntino. A pesar de vivir en la capital de la República, se manifestaban plenamente comprometidos con la realidad de su provincia, a la que veían sumida en un estado de postergación política y económica, que la había hecho descender de la posición que había ocupado en el pasado, cuando, siendo parte del viejo litoral histórico, tuviera una amplia y destacada participación en la formación del estado argentino. La percepción de ese retroceso en la jerarquía de "provincia organizadora" implicaba un rudo golpe a las expectativas de la sociedad correntina.

Los objetivos que se fijó el naciente Centro Correntino "General San Martín", dan cuenta de esta percepción; además de la finalidad de instituir un homenaje permanente a la memoria del general San Martín, resaltando su condición de hijo de Corrientes, y de apoyar la ejecución de la ley, pretendía mantener unidos a los correntinos residentes en la capital, poniéndolos al servicio de los intereses de la provincia; fomentar todas las iniciativas que pudieran redundar en su progreso y el del país; gestionar o apoyar toda gestión orientada a reintegrar a la provincia el territorio de Misiones y difundir las tradiciones y la historia de su provincia, apoyando las iniciativas culturales de sus miembros. Con el tiempo, y por la influencia social y 
política de quienes lo integraban, se convirtió en representante de las distintas asociaciones correntinas ante los organismos del estado nacional, y realizó numerosas gestiones, destinadas fundamentalmente a la obtención de subsidios. ${ }^{32}$

La comisión directiva estaba presidida por Benjamín S. González. ${ }^{33}$ Aunque se presentaba como una entidad apolítica, sus miembros tenían una clara posición en este sentido, ya que estaban representados los dos principales partidos políticos provinciales, el autonomista y el liberal. Más allá de las diferencias generacionales, los asociados tenían fuertes lazos con el Colegio Nacional de Corrientes, máximo centro educativo de la provincia, del que la mayoría eran egresados, la experiencia de haber participado en asociaciones culturales y recreativas, y lazos de amistad fortalecidos, en muchos casos, por haber compartido la vida universitaria. ${ }^{34}$

En agosto, el Centro encabezó la celebración de un gran acto en homenaje al general San Martín realizado en la plaza de Retiro, al pie de su estatua. Participaron los miembros del Centro, los legisladores nacionales de Corrientes y una delegación especial de la provincia, y estuvieron representados el Ministerio de Guerra, el Círculo Militar, el Centro Naval, la Sociedad Damas Patricias, la Sociedad Pro Patria, la Federación Universitaria, la Federación Nacional de Estudiantes Secundarios y diversos colegios y centros particulares, entre ellos el de Guerreros del Paraguay. El Consejo Nacional de Educación se adhirió al homenaje, disponiendo la concurrencia de escolares acompañados de sus maestros, como se acostumbraba en las fiestas patrias, así como la realización en esa jornada de clases especiales dedicadas a la figura de San Martín. ${ }^{35}$ El homenaje se inició con un oficio religioso celebrado por la mañana en la catedral Metropolitana, con la presencia de todas las delegaciones y representantes, que culminó con el desfile de los asistentes ante el sepulcro que guarda los restos del Libertador, donde una delegación del Centro Correntino depositó una ofrenda floral. Por la tarde, los actos se desarrollaron en la plaza San Martín, en la que se formaron en corporación los escolares, las compañías de los regimientos 3 y 4 de infan-

32 Centro Correntino General San Martín, Memoria Anual, Agosto 1916-1917, Buenos Aires, 1917.

33 La comisión directiva estaba integrada por Miguel Susini, Antonio Ramayón, José C. Verón, Manuel Vicente Figuerero, Delfino Pacheco, Benjamín T. Solari, Joaquín Rubianes, Juan G. Valenzuela, Juan R. Galarza, Walter Elena, entre otros.

34 Cit. en Memoria Anual.

35 Centro Correntino General San Martín, Homenaje a San Martín en el 65 aniversario de su muerte, Buenos Aires, 1915, págs. 9-11. 
tería y un escuadrón del regimiento de granaderos a caballo, rodeados por un público numeroso. Al pie del monumento fue colocada una placa con una significativa expresión: "Corrientes al más grande de sus hijos".

La tribuna fue ocupada por los miembros del Centro, representantes y delegaciones. Desde ella se pronunciaron discursos que giraron en torno a cuatro ejes fundamentales, de los cuales, sólo uno estaba ligado esencialmente a la naturaleza del acto de homenaje:

- reafirmar la condición de correntino del general San Martín.

- reivindicar el lugar que debía ocupar Corrientes en el contexto nacional.

- manifestar el desacuerdo del gobierno correntino con la realidad nacional.

- pronunciarse a favor de la restitución del territorio misionero a la provincia de Corrientes.

El discurso del doctor Ramón A. Beltrán, diputado nacional y autor del proyecto sobre la casa natal de Libertador, que fuera invitado por el Centro a integrar la comisión de homenaje, pretendió reafirmar la posición de la provincia respecto del origen de San Martín, aseverando que era correntino por haber nacido en Yapeyú, Elevó una queja sobre la forma en que se enseñaba en las escuelas ese aspecto de la biografía del prócer, puesto que al ser presentado como "misionero" podían generarse confusiones que ligaran su lugar de nacimiento al territorio nacional de Misiones. Pero en todo momento se silenciaba la situación jurisdiccional de ese territorio al momento del nacimiento del futuro padre de la patria. En el marco de los permanentes reclamos por la restitución a la provincia del territorio de Misiones, se pretendía imponer una Yapeyú olvidada de su pasado misionero y asimilada totalmente a la tradición de Corrientes:

“...San Martín fue correntino, por la raza, por el ambiente, por el territorio en que nació y hasta por el carácter reservado, reflexivo, el "vaso opaco que encerraba el fuego oculto en el interior del alma", según la feliz expresión del general Mitre, su ilustre historiador". ${ }^{36}$

En este sentido, resulta aún más explícito el discurso de Juan Balestra, pronunciado al pie de la estatua del Libertador, en el homenaje realizado por los correntinos, en el año del centenario de la independencia, al referirse a la destrucción de que había sido objeto el poblado que pretendía elevarse a la condición de monumento de la memoria sanmartiniana:

36 Homenaje, pág. 19. 


\begin{abstract}
"Ni un hogar, ni un morador, ni un recuerdo escrito quedaba en las solitarias y derruidas ciudades de piedra! Pero quedaban la patria y la América para hacer del hijo de Yapeyú, el primero de sus hombres; y quedaba la raza, la tradición y el sitio del primer hogar materno en Corrientes, a la cual perteneció siempre étnica y geográficamente Yapeyú. No están mal pues sus hijos reclamando un puesto entre las columnas que pasan entonando canciones de gloria ante esta estatua....". ${ }^{37}$
\end{abstract}

El discurso de Joaquín Rubianes, quien fuera la voz del Centro Correntino y del gobierno de la provincia en el acto, dejó entrever los objetivos hasta entonces subyacentes, tanto del homenaje como de la reivindicación. Rubianes, miembro del partido liberal y representante de la generación del centenario, en 1913 había presentado a la convención constituyente de su provincia un Programa Orgánico de Reacción Federalista, que excedía ampliamente las facultades de ese cuerpo y revelaba las preocupaciones compartidas por los hombres de su generación. En él proponía una serie de mecanismos tendentes a limitar las intervenciones federales a los estados provinciales, puesto que eran utilizadas como instrumentos políticos al servicio de los intereses de las elites y los partidos; esta propuesta se realizaba desde una de las provincias que, con anterioridad a 1880, había sido "víctima" frecuente del uso de ese recurso por parte del gobierno federal; unas veces, para solucionar sus problemas internos y, en otras ocasiones, debido a sus malas relaciones con el gobierno central. También hacía referencia, en los fundamentos del proyecto, a la necesidad de devolver a las provincias "su plena capacidad financiera" entre otras cuestiones que debían garantizar el ejercicio pleno de la autonomía..$^{38}$

Su discurso de 1915, al pie del monumento a San Martín, lejos de reparar en la trayectoria del héroe, mantuvo esa tesitura. Luego de un análisis de la realidad nacional, vista desde las expectativas no realizadas de la elite a la que representaba, reiteró la serie de reclamos que desde Corrientes se venían realizando en el último tercio del siglo XIX, haciendo explícito una vez más el sentimiento de postergación que le provocaba la contemplación de las desigualdades.

Cuestionó el progreso argentino, del que la elite nacional se había vanagloriado en la celebración del centenario de la revolución de mayo, y

37 Balestra, Juan: San Martín. Discurso pronunciado ante el monumento del héroe en representación del "Centro Correntino General San Martín”. 17 de agosto de 1916, Buenos Aires, 1916, págs. 7-8. (La bastardilla es nuestra)

38 Rubianes, Joaquín: "Programa Orgánico de Reacción Federalista", en Nosotros, Buenos Aires, año VII, tomo IX, n. ${ }^{\circ}$ 9, 1912, págs. 398-414. 
lejos del envanecimiento por los logros alcanzados, puso el acento en la falta de equidad evidente en ese desarrollo, debida a la adopción de un esquema económico y una política de obras públicas que favorecían a la región que se hallaba integrada al mercado mundial y excluía a las demás provincias que, como Corrientes, se veían privadas de los medios necesarios para alcanzar un grado de progreso material equivalente.

Por ello, en momentos de agitación nacionalista, en lugar del patriotismo optimista, que "pensando en el comienzo obscuro, se deslumbra ante el cuadro del presente", proponía ejercitar un patriotismo exigente que, no conforme con los logros obtenidos, "apenas pisa la meta de un ideal, ya pone el oído atento a las nuevas palpitaciones del pueblo, ya escruta, con mirada resuelta, nuevos caminos en los horizontes inmensos de la vida nacional". ${ }^{39}$ Esta concepción del patriotismo, adoptada desde la función pública, debía contribuir a superar las deficiencias del progreso alcanzado, eliminando los contrastes. A la luz de la realidad de su provincia, sostenía que mientras el país se envanecía "por los millares y millares de kilómetros de cintas de acero... que realizan el pensamiento de Alberdi", en algunas regiones, como en Corrientes, las líneas férreas resultaban tan insuficientes como los caminos, los puentes y las inversiones de capital, y no existían las condiciones requeridas para su desarrollo económico.

Estos discursos fueron seguidos por breves alocuciones de los representantes del Ateneo Hispanoamericano, de la Federación de Estudiantes Secundarios y de la Federación Nacional de la Juventud, que insistieron en reconocer la legitimidad del homenaje tributado por los correntinos a San Martín en su condición de "comprovinciano". ${ }^{40}$ Finalizados los discursos, los escolares, las tropas, las delegaciones y la concurrencia desfilaron frente al monumento.

Paralelamente, en la ciudad de Corrientes, el Centro de Estudiantes Secundarios del Colegio Nacional, que desde 1910 lideraba las iniciativas cívicas juveniles, fue el promotor de los actos realizados al pie del monumento de la plaza Mayo y de la procesión cívica de la que participaron las escuelas primarias y secundarias y una numerosa concurrencia. La iniciativa estudiantil obtuvo la adhesión del Consejo de Educación, que ordenó se impartieran clases especiales dedicadas a la figura de San Martín y promovió la asistencia a los actos.

39 C.C.G.S.M.: Homenaje..., pág. 21

40 Ibídem, pág. 28. 
Las palabras pronunciadas en la oportunidad por Hernán Félix Gómez, en representación del Centro de Estudiantes Secundarios, serían tomadas como modelo para los discursos escolares posteriores; en ellas se buscaba establecer, en tono poético, la impronta del medio correntino sobre la personalidad del héroe:

"El hado de la selva correntina canta... que una vez se reunieron en el norte de la Patria los genios tutelares de esta región... y buenos, generosos, decidieron dar a los pueblos de la región del Plata un hombre redentor. El trópico, enamorado del propósito, buscó la cuna. La eligió en el seno de la Selva Misionera, allí donde el Uruguay podría cantar el himno supremo de las predestinaciones....". ${ }^{41}$

En los años sucesivos, se reiteraron los homenajes al Libertador en el aniversario de su fallecimiento, tanto en Buenos Aires como en Corrientes. El Centro Correntino, al disgregarse, sería reemplazado en esta tarea por la Asociación de Damas Correntinas de la Confederación Nacional de Beneficencia, actividades que "han servido para despertar los sentimientos patrióticos, bastante adormecidos en la capital de la República por su gran población cosmopolita". ${ }^{42} \mathrm{Al}$ mismo tiempo, se realizaron gestiones tendentes a instaurar la conmemoración del día dedicado al general San Martín en el calendario cívico de todo el país; se solicitó a las Direcciones Generales de Escuelas de las catorce provincias y al Consejo Nacional de Educación que promovieran la celebración en las escuelas de su dependencia.

Dentro del sistema educativo correntino, se estableció una línea histórica que unía la figura de San Martín con los "héroes de la cruzada libertadora", fundamentalmente, con Genaro Berón de Astrada, "el mártir de Pago Largo". Esto se advierte en el discurso de Marcelino Elizondo, representante del Consejo Nacional de Educación en Corrientes:

“¡Alabada seas, ahora y siempre tierra bendita, cuna de héroes y altar de mártires! Yo te venero y rindo culto a tu bandera, que es la bandera de mi patria: tu imagen pura... jamás será empañada con el turbión de tiranos. El sol que te alumbra es el sol de Mayo... De tu seno virginal, fertilizado con la sangre generosa de tus hijos, surgió el árbol de la libertad. San Martín, Juan Bautista Cabral y Berón de Astrada sintetizan la trilogía de tus glorias....".33

41 Gómez, Hernán Félix: "El Redentor Americano", en Páginas de historia, Corrientes, 1928, pág. 36

42 RePÚbliCA ARgEnTiNA. Cámara de Diputados. Diario de Sesiones, Buenos Aires, 1932, t. IV, pág. 782.

43 Elizondo, Marcelino: "A Corrientes", en Revista La Escuela, Consejo Superior de Educación, Corrientes, septiembre de 1915, pág. 2444. 
El gobernador Benjamín S. González, ${ }^{44}$ quien se preocupó especialmente por la preservación de la memoria histórica y la difusión de la historia provincial, en 1926, declaró feriado el 17 de agosto y organizó el primer homenaje de carácter oficial. Entre los fundamentos del decreto, se sostenía que "nacido el Gral. San Martín en Corrientes, ella debe ser la primera provincia argentina que debe tributar el homenaje de gratitud y glorificación hacia el libertador con la rememoración de la fecha de su muerte". Se adhirieron los gobiernos de otras provincias y, en el caso de Santiago del Estero y Córdoba, también declararon feriado. Santa Fe, por su parte, ya lo venía haciendo desde 1921, con peregrinaciones a San Lorenzo. En esa ocasión asistieron representaciones de todas las provincias, del ejército y la armada nacional. En la iglesia catedral, donde se realizó el tedéum, se levantó el altar de la patria, obra del artista Adolfo Mors. Finalizado el oficio religioso, las tropas marcharon a plaza Mayo, seguidas por las delegaciones portadoras de coronas, las autoridades provinciales, un grupo de damas, escuelas y sociedades extranjeras. Al pie del monumento, se pronunciaron varios discursos, seguidos del desfile militar. Por la tarde, la policía realizó su tributo al sargento Cabral. Las actividades se completaron con partidos de fútbol y una recepción en casa de gobierno para los oficiales de la cañonera "Paraná" y del regimiento de Granaderos a Caballo que habían participado del homenaje. ${ }^{45}$ En los años siguientes, se seguirían repitiendo estos actos.

\section{Nueva polémica en torno a Yapeyú: la culminación del debate y la imposición del día de San Martín}

Se continuaron también los esfuerzos por convertir a Yapeyú en un lugar de memoria. El gobernador Mariano I. Loza se propuso construir, mediante la contribución popular, una escuela en la localidad de Yapeyú, que debía llevar el nombre de "General San Martín" y sería inaugurada el

44 Benjamín S. González (1925-1929). Presidió el Centro Correntino General San Martín, en Buenos Aires. Durante su gestión como gobernador de la provincia se publicaron numerosas obras históricas y se realizaron ediciones documentales; se organizó en la provincia el Tercer Congreso de Historia Argentina; se dispuso la determinación de los monumentos y lugares históricos en el territorio provincial y se proveyó su custodia; se crearon el Museo Histórico y el Museo Colonial

45 Véase Gobierno de la Provincia de Corrientes: Homenaje a San Martín. Actos conmemorativos realizados con motivo de la celebración del $76^{\circ}$ aniversario del fallecimiento del General don José de San Martín, Corrientes, 1927. 
17 de agosto de 1916, en homenaje conjunto al Libertador y al primer centenario de la Independencia.

El 9 de septiembre de 1922, en el centenario de la independencia de Brasil, el Colegio Nacional de Corrientes organizó un acto de homenaje al Brasil en Yapeyú, al que se adhirió el gobierno provincial y asistieron delegaciones de las localidades fronterizas de Uruguayana e Itaquí. San Martín fue recordado allí como símbolo de la unión americana. Se realizó una colecta de fondos entre los presentes para construir el templete protector de las ruinas y se constituyó una comisión ejecutora del mismo, patrocinada en la capital federal por el Ateneo Hispano Americano. El periódico Crítica, de Buenos Aires, se hizo eco del movimiento a través de varios artículos; refería que en Corrientes ese era el tema del día y que se sucedían las peregrinaciones a la casa de San Martín desde todos los pueblos, especialmente los de la zona del río Uruguay. ${ }^{46}$

Hernán F. Gómez, uno de los historiadores correntinos de mayor relieve, fue un activo promotor de estas acciones. Realizó investigaciones arqueológicas que, unidas al material que le aportaron quienes ya habían trabajado el tema, originaron la obra que reabrió la polémica: en 1923, aparece Yapeyú y San Martín, destinada a confirmar la tradición popular que establecía la ubicación del solar del prócer, a través de una revisión de la historia de Yapeyú. Se propuso mostrar cómo el sitio había sido residencia, sin discontinuidades, de una población que conservó la tradición sobre la cuna de San Martín. Escrita al calor del momento, la obra realiza un estudio crítico de la bibliografía sobre el tema. Unido al testimonio brindado por la tradición oral, a la cual otorga un lugar central, Gómez recurre al estudio del terreno, de las ruinas y efectúa la reconstrucción de la planta del pueblo. En la misma

"la casa de los gobernadores, cuna del libertador, ocupa una situación de privilegio. Situada en el segundo patio del colegio, independiente de las celdas de los padres que atendían las cuestiones de la religión, del trajín de la sacristía y de la actividad de los talleres y de la escuela, que cierran el primer grupo de edificios, tiene enfrente el silencio de los almacenes y al flanco, con frente a la plaza, las casas del Cabildo. Hacia el oriente la amplia playa y el cristal risueño del río, le aseguran toda la independencia necesaria para los hábitos severos del funcionario y su familia, con puerto accesible a sus placeres y seguridad". ${ }^{77}$

46 "La casa natal de San Martín y la prueba histórica", en Crítica, Buenos Aires, 23 de septiembre de 1922.

47 Gómez: Yapeyú..., pág. 100 
Advierte sobre los desmoronamientos periódicos de la ruina, "cuyas piedras al despeñarse suenan hondo en la conciencia nacional". ${ }^{48}$

Esta obra fue severamente criticada por el historiador Ernesto Quesada, quien juzgó que su bibliografía era incompleta y que el autor se contentaba con afirmar, sin analizar. Y señalaba que, como miembro de la Comisión de Homenaje que se trasladó a Yapeyú, observó que todas eran referencias vagas: "no hay tradición fidedigna que permita asegurar cuál fue el sitio de la casa donde nació San Martín". ${ }^{49}$ Leguizamón, por su parte, bajo el título de Las ruinas de Yapeyú. Nuevas comprobaciones, insistiría en que "la cuna desconocida permanece en el misterio". ${ }^{50}$

Dada esta situación, el Poder Ejecutivo Nacional designó una comisión presidida por Leguizamón e integrada por Antonio Dellepiane, Hernán Gómez, Eduardo Maldonado, Martín S. Noel y Enrique Udaondo, en diciembre de 1923, para aunar criterios. Gómez, a través de documentos, periódicos y fotografías, buscó demostrar el valor de la tradición popular y la persistencia del asentamiento en Yapeyú. Junto con Maldonado, dieron conferencias sobre el tema, que alcanzaron amplia repercusión periodística. Leguizamón, Noel y Udaondo informaron por separado, sin modificar las conclusiones obtenidas en 1915.

Juan W. Gez y Juan Esteban Guastavino volvieron a abonar esta posición, como lo expusieran en Las ruinas de Yapeyú, el primero, y en La cuna apócrifa. Tradición sin antecedentes, el segundo, desde las páginas de $L a$ Nación, en 1924. Finalmente, en 1929, el gobierno de Corrientes declaró monumento provincial "las ruinas de la casa de los gobernadores de Yapeyú, donde naciera el General San Martín", que habían sido expropiadas por el gobierno provincial en 1925.

Habría que esperar hasta la década de 1930 para que las dos iniciativas correntinas alcanzaran concreción desde el ámbito nacional. Precisamente, la operación de política histórica de entronización de San Martín se completa en los años 30, durante la presidencia del general Agustín P. Justo. Ricardo Rojas publicó El Santo de la Espada (1933) y José Pacífico Otero concluyó su monumental Historia del Libertador Gral. San Martín y fundó el Instituto Sanmartiniano, en el cual, en ese momento, no tuvo eco

48 Ibídem, pág. 174

49 Quesada, Ernesto. “Contestación a Hernán Félix Gómez”, en Nosotros, Buenos Aires, n. ${ }^{\text {}}$ 174, noviembre de 1923, págs. 332-333.

50 Citado por Canter, Juan: "Biobibliografía de Martiniano Leguizamón”, en Boletín del Instituto de Investigaciones Históricas, Buenos Aires, t. XXVI, año XX, n. ${ }^{\circ}$ 89-92, 2. a parte, 1942, pág. 759. 
la postura correntina. La Junta de Historia y Numismática Americana, transformada en Academia Nacional de la Historia, emprendió la redacción de la Historia de la Nación Argentina. Allí se terminó de definir la primacía de San Martín, distanciado de un conjunto de "figuras menores" y convertido en expresión esencial del ser nacional.

En 1932, el entonces diputado nacional Benjamín S. González, presentó a la cámara un proyecto de ley declarando fiesta cívica nacional el día 17 de agosto. Al fundamentar su proyecto, destacó que

"Estaba destinado, Sr. Presidente, que a Corrientes le habría de corresponder el honor de dar a nuestro país el brazo inflexible que aseguraría el cumplimiento de los nobles ideales de los hombres de Mayo. A punto de sucumbir a manos de los españoles en San Lorenzo, lo salva un heroico correntino...y brinda así a la posteridad el símbolo del desinterés, del patriotismo, de la abnegación y de las más acrisoladas virtudes". ${ }^{51}$

Sin embargo, cuando, al año siguiente, el presidente Agustín P. Justo oficializó el 17 de agosto como "Día de San Martín", sólo tuvo en cuenta una presentación del Instituto Sanmartiniano, en la cual no se hacía ninguna referencia a las propuestas correntinas. El presidente del Instituto fue la figura central de los actos conmemorativos y quien se encargó de fundamentar la instauración de esta fecha patria:

“...intentamos responder a un imperativo de civilización, de justo y oportuno nacionalismo, pero con ánimo desprevenido de toda lucha de clases y de partidos a fin de hacer eficiente y real la unidad de la familia argentina. Queremos que exista una patria grande y digna, y queremos que a su frente se destaque como luminaria suprema la figura de ese Libertador que creó la epopeya y fundamentó así todos los estimulantes posibles para que, estudiándola y escudriñándola, los cultores del pensamiento, de la literatura y del arte, se asocien en el esfuerzo educador de su obra". ${ }^{52}$

Otero señalaría que esta era la primera gran demostración cívica en homenaje al Libertador, desconociendo también los actos anteriores organizados por los correntinos. Corrientes se veía nuevamente desplazada en sus iniciativas. No obstante, al año siguiente, González repetiría su presentación, en la cual tampoco aludía al Instituto Sanmartiniano. En ese mismo año, presentó un proyecto de declaración para que se procediera a la brevedad a la ejecución de las obras proyectadas en Yapeyú.

51 REPÚBliCA ARGENTINA. Cámara de Diputados. Diario de Sesiones, Buenos Aires, 1932, t. IV, pág. 787.

52 Otero, José Pacífico: La vida y la muerte del héroe, Buenos Aires, 1933, págs. 13-14. 
Por su parte, el diputado santafesino Plácido Lazo presentó un proyecto para declarar monumento nacional al convento de San Carlos, con el fin de destinarlo a un museo sanmartiniano, y en el terreno adyacente, que se denominaría "Campo de la gloria", se debía erigir un monumento. Frente al "mal entendido fanatismo patriótico que tantas veces lleva a deificar piedras o ruinas con aires de santuarios que no guardan la menor relación con la vida evolutiva del país...si existe algo en nuestra nación, que pueda llevar con holgura y dignidad el timbre de monumento nacional, ese es precisamente el convento" ${ }^{53}$ Se hacía referencia así, elípticamente, a las ruinas de Yapeyú. ${ }^{54}$

Finalmente, el congreso destinaría los fondos para la construcción de un templete protector de las ruinas en Yapeyú, que estuvo a cargo de la Dirección General de Arquitectura del Ministerio de Obras Públicas, que fue inaugurado el 17 de agosto de 1938. Un día antes, se promulgaba la ley nacional que declaraba feriado esa fecha. Según la crónica periodística, Yapeyú recibió una extraordinaria afluencia de público pero, llamativamente, no hubo una representación significativa del gobierno nacional, que se concentró en los actos en Buenos Aires, que tuvieron mayor repercusión, restándole trascendencia a la ceremonia inaugural ${ }^{55}$ Formalmente, los objetivos de Corrientes se habían logrado: edificar un lugar de memoria sanmartiniana en su territorio e instaurar una nueva fecha en el calendario cívico, pero la provincia no logró ejercer su protagonismo en dichas iniciativas.

\section{Conclusiones}

El movimiento generado por la provincia de Corrientes en torno a la figura de San Martín se inserta en el contexto de su lucha contra el centralismo de Buenos Aires. En esa lucha, la elite correntina, mediante la tenaz defensa de sus tradiciones, perseguía el reconocimiento en el ámbito nacio-

53 REPÚbliCA ARGEnTINA. Cámara de Diputados. Diario de Sesiones, Buenos Aires, 1933, t. II, pág. 740 .

54 El convento de San Lorenzo fue declarado Monumento Nacional por ley n. ${ }^{\circ} 12.648$ del 2 de octubre de 1940. La misma incluía el campo contiguo, donde se libró la batalla. El campamento de El Plumerillo en Mendoza lo fue un año más tarde, el 6 de diciembre de 1941, por Decreto n. ${ }^{\circ}$ 107.512. Ver Vigil: Los monumentos..., págs. 282 y 434

55 Para reconstruir dicho acto, sólo se cuenta con los periódicos nacionales, que le asignaron un breve espacio a Yapeyú. Lamentablemente, no contamos con los periódicos provinciales de esa fecha, ni con registros de los discursos pronunciados en la oportunidad. 
nal de la importancia de la provincia como entidad autónoma y como factor clave en el proceso de organización institucional argentino. Los monumentos públicos, las conmemoraciones, los peregrinajes, la reconstrucción de tradiciones orales y la determinación de lugares de memoria fueron distintas herramientas utilizadas por la elite correntina en una desigual competencia con Buenos Aires por el control de la memoria argentina.

Frente a la construcción de un San Martín esencialmente "americano", Corrientes revalidaba, en primer término, su condición de correntino, atribuyéndole a la misma la transmisión de las virtudes y los valores que le permitieron convertirse en un héroe continental. De allí que la historiografía correntina se ocupó solamente del tema de la "cuna del héroe", sin abordar otras etapas de su itinerario biográfico, en las cuales se perdía su débil ligazón con Corrientes y se reforzaban sus vínculos con otras provincias, como Santa Fe y Mendoza. Por otro lado, dicha temática le servía de instrumento para sus reivindicaciones políticas sobre el territorio de Misiones.

Al mismo tiempo que se efectuaba la construcción de una historia nacional desde Buenos Aires, en Corrientes se elaboraba una historia provincial que sostenía que en la historia argentina se dieron paralelamente dos procesos: uno que iba dando forma a la existencia común de los pueblos y otro que, lentamente, manifestaba la existencia de cada provincia. San Martín y Genaro Berón de Astrada eran los máximos representantes de cada uno de ellos. 